\title{
Community knowledge, perceptions, and practices regarding malaria and its control in Jabi Tehnan district, Amhara Region, Northwest Ethiopia
}

\author{
Abebe Asale ${ }^{1 *}\left(\mathbb{D}\right.$, Zewdu Abro ${ }^{1}$, Bayu Enchalew ${ }^{1}$, Alayu Teshager ${ }^{1}$, Aklilu Belay $^{2,3}$, Menale Kassie $^{2}$ and \\ Clifford Maina Mutero ${ }^{2,3}$
}

\begin{abstract}
Background: Use of long-lasting insecticidal nets (LLINs), indoor residual spraying (IRS), community-based malaria education, prompt diagnosis and treatment are key programme components of malaria prevention and control in Ethiopia. However, the effectiveness of these interventions is often undermined by various challenges, including insecticide and drug resistance, the plasticity of malaria vectors feeding and biting behaviour, and certain household factors that lead to misuse and poor utilization of LLINs. The primary objective of this study was to document households' perceptions towards malaria and assess the prevalence of the disease and the constraints related to the ongoing interventions in Ethiopia (LLINs, IRS, community mobilization house screening).
\end{abstract}

Methods: The study was conducted in Jabi Tehnan district, Northwestern Ethiopia, from November 2019 to March 2020. A total of 3010 households from 38 villages were randomly selected for socio-economic and demographic survey. Focus group discussions (FGDs) were conducted in 11 different health clusters considering agro-ecological differences. A total of 1256 children under 10 years of age were screened for malaria parasites using microscopy to determine malaria prevalence. Furthermore, 5-year malaria trend analysis was undertaken based on data obtained from the district health office to understand the disease dynamics.

Results: Malaria knowledge in the area was high as all FGD participants correctly identified mosquito bites during the night as sources of malaria transmission. Delayed health-seeking behaviour remains a key behavioural challenge in malaria control as it took patients on average 4 days before reporting the case at the nearby health facility. On average, households lost 2.53 working days per person-per malaria episode and they spent US\$ 18 per person per episode. Out of the 1256 randomly selected under 10 children tested for malaria parasites, 11 (0.89\%) were found to be positive. Malaria disproportionately affected the adult segment of the population more, with $50 \%$ of the total cases reported from households being from among individuals who were 15 years or older. The second most affected group was the age group between 5 and 14 years followed by children aged under 5, with 31\% and 14\% burden, respectively.

\footnotetext{
*Correspondence: aasale@icipe.org

1 International Center of Insect Physiology and Ecology, Addis Ababa, Ethiopia
}

Full list of author information is available at the end of the article

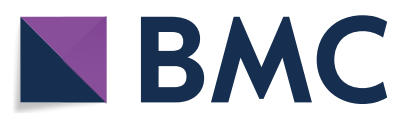

(c) The Author(s) 2021. Open Access This article is licensed under a Creative Commons Attribution 4.0 International License, which permits use, sharing, adaptation, distribution and reproduction in any medium or format, as long as you give appropriate credit to the original author(s) and the source, provide a link to the Creative Commons licence, and indicate if changes were made. The images or other third party material in this article are included in the article's Creative Commons licence, unless indicated otherwise in a credit line to the material. If material is not included in the article's Creative Commons licence and your intended use is not permitted by statutory regulation or exceeds the permitted use, you will need to obtain permission directly from the copyright holder. To view a copy of this licence, visit http://creativecommons.org/licenses/by/4.0/. The Creative Commons Public Domain Dedication waiver (http://creativeco mmons.org/publicdomain/zero/1.0/) applies to the data made available in this article, unless otherwise stated in a credit line to the data. 
Conclusion: Despite the achievement of universal coverage in terms of LLINs access, utilization of vector control interventions in the area remained low. Using bed nets for unintended purposes remained a major challenge. Therefore, continued community education and communication work should be prioritized in the study area to bring about the desired behavioural changes.

Keywords: Malaria prevalence, Malaria knowledge, Behavioral change, Control strategy, Ethiopia

\section{Background}

Malaria is a major threat in Ethiopia with high health and economic burden, especially among poor households. It also imposes a fiscal burden on the national government due to public health expenditure related to treatment and prevention of the disease. In 2017 alone, 71 million Ethiopians were at risk, 2.7 million people were infected, and 5300 died due to malaria [1]. Thus, malaria profiling provides insights that can help design targeted strategies to reduce the impact of the disease.

Currently, Ethiopia relies on multiple interventions namely community empowerment and mobilization, vector control using LLINs and IRS, prompt diagnosis and treatment and disease surveillance to curb the burden of the disease [1]. However, insecticide resistance [2], drug resistance [3], the plastic nature of malaria vectors feeding and biting behaviour [4], and household factors hindering the proper use of LLINs [5] constitute series challenges which undermine the efficacy of various interventions. Therefore, it is imperative to explore new approaches and tools to augment the existing malaria control interventions.

One of the emerging approaches being evaluated by researchers, and malaria programmes in Africa is house screening (HS), involving the screening of open eaves, windows, and doors of houses [6-11]. HS reduces malaria among house occupants by serving as a physical barrier to mosquito entry into house. HS is not a new innovation, but it has never got enough attention as a practical intervention for malaria prevention at household level [11-14].

There are limited research reports that focus on malaria profiling in Jabi Tehnan district and their aims, delimitations and contexts also varied. For instance, Animut et al. conducted a study focused on hospital-based data to determine the causative agent of acute febrile illness in the area and reported malaria as a primary source of morbidity in the area [15]. Ayalew et al. conducted a malaria cross-sectional survey in Jiga area, which was limited to three kebeles and reported a $2.8 \%$ prevalence rate [16]. Further two studies were conducted by Animut et al. [17, 18]. These studies do not comprehensively reflect the malaria profile in the area as the former mainly focuses on peoples' perception of basic malaria information. The latter mainly describes the dry season vector information in the area. This paper aims at documenting peoples' perception towards malaria, the prevalence of the disease, and the constraints related to the ongoing interventions such as access and utilization in Northwest Ethiopia.

\section{Methods \\ Description of the study area}

The study was conducted in Jabi Tehnan district in Amhara Regional State, Northwestern Ethiopia from November 2019 to March 2020. The district population was 211,516 in 2017, with an average annual growth rate of $2.8 \%$ [19]. The district is divided into 38 kebeles, the smallest administrative units of the country, and has three town administrative towns. More than $90 \%$ of the people in the district live in rural areas practicing mixed farming.

The district covers $1170 \mathrm{~km}^{2}$ at an altitude of between 1500 and $2300 \mathrm{~m}$ above sea level. The topography is classified as $65 \%$ flat, $15 \%$ mountainous, $15 \%$ undulating, and $5 \%$ valley [20]. The average annual rainfall is $1250 \mathrm{~mm}$ and has a bi-modal distribution, with the first rainy season lasting between March to April and the second lasting for 4 months from mid-June to mid-September. Minimum and maximum temperatures are $14{ }^{\circ} \mathrm{C}$ and $32{ }^{\circ} \mathrm{C}$, respectively [20]. The weather, topography, and agroecology of the district are favorable factors for the presence of mosquito populations (Fig. 1). Mixed socioeconomic activities (agriculture and animal husbandry) are practiced in the area. The area is known for keeping live stock in either close proximity or with in the human residence as it is mostly practiced in other parts of the country [21, 22].

Malaria is one of the major causes of morbidity and mortality in the district, alongside HIV/AIDS, Tuberculosis, cardiovascular, lower respiratory, and diarrheal disease [23]. Malaria prevalence in the area was $2.8 \%$ in 2013 [16]. This prevalence is higher than the average for Amhara Regional State (1.1\%), where this district is situated, and the country's average prevalence (1.2\%) [24]. Despite a decline in malaria burden in recent years, the disease remains a top health threat, with annual cases surpassing 20,000 in 2017 in the district (unpublished data from District Bureau of Health). High hospitalbased parasite positivity rates up to $65.4 \%$ (both clinical 


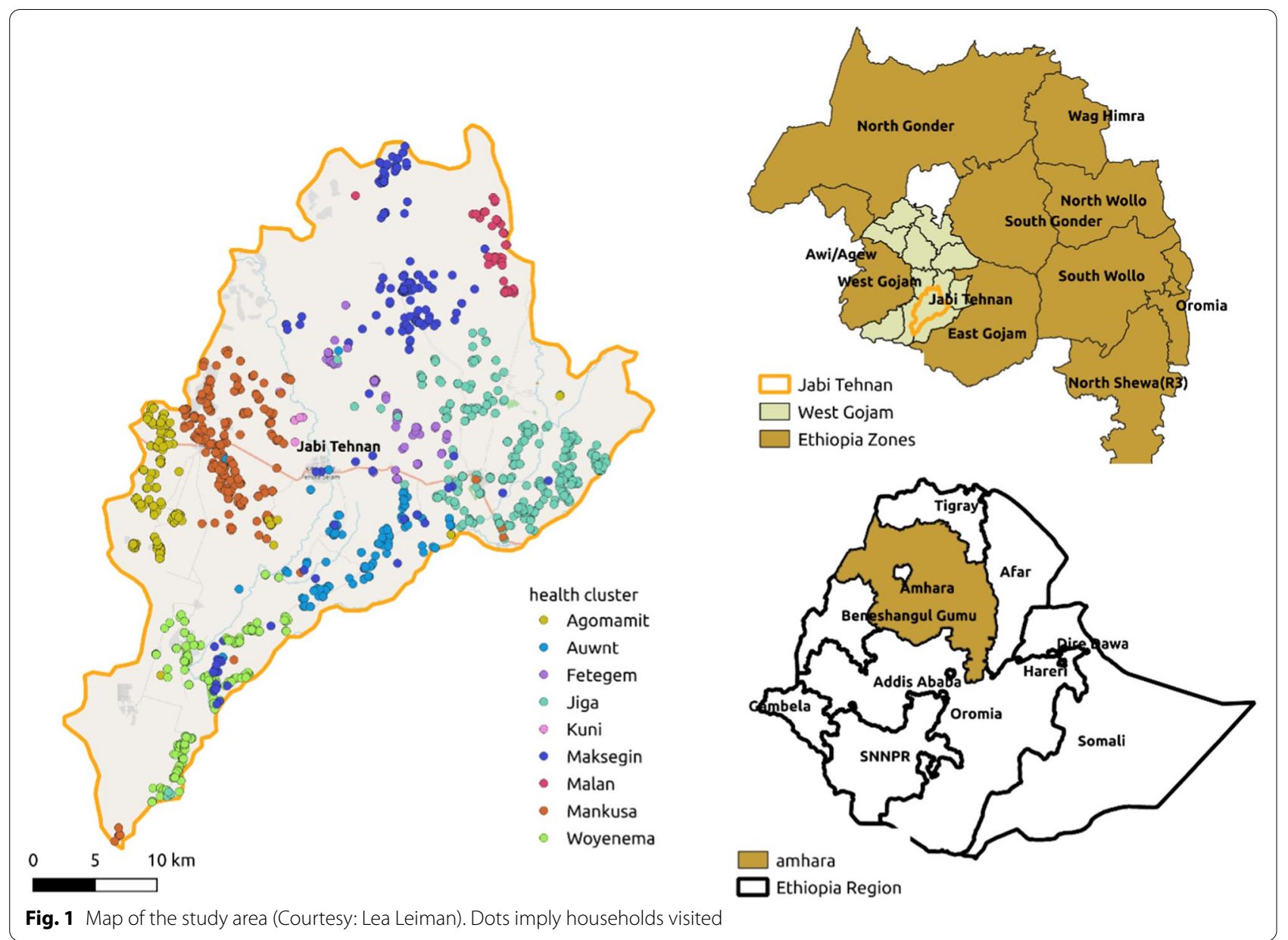

and microscopy combined) was reported from health facilities.

Anopheles arabiensis is the dominant malaria vector, while Anopheles pharoensis has a secondary role in transmission [18]. Both vector species are known for their zoophagic [25] and anthropophagic behaviour $[21,26]$. The former species is commonly known for its opportunistic feeding and resting behaviour [25], whereas the latter is widely considered as zoophagic and exophilic species [21]. In Ethiopia, An. arabiensis is known for its early and late night biting activity though it continues to be active throughout the night [27-29]. According to a preliminary assessment, cattle, sheep, donkey and poultry are commonly raised domestic animals in the area.

The Ethiopian government is committed to eliminating malaria in low and intermediate transmission areas such as the Jabi Tehnan district [30]. Documenting the progress by triangulating various data sources will help understand the malaria elimination effort status and the prospect of attaining this government plan [16].

\section{Data collection methods Household surveys}

The study area had 38 kebeles, which were for purposes of this research further sub-divided into 115 sub-kebeles. For each kebele, up-to-date census of the chairperson and members of one-to-five groups were prepared and used to provide the required sampling frame for different surveys and FGD. The one-to-five groups are local level farmers' organizations. Everyone is organized into a group of five people and a chairperson. These groups identify the development priorities of their respective community. They plan all the activities that need to be done in groups and individually. Every 3 days, the chairs of each group meet with the development committee of their respective kebele. Each group evaluate their performance every 15 days. The chairpersons of the one-to-five groups are the nodes of communication.

Between 3 and 56 households per sub-kebele were randomly selected for the surveys. The number varied from sub-kebele to sub-kebele depending on the number of one-to-five groups and the population of sub-villages. 
A total of 3010 households were interviewed from the selected kebeles in June and July 2019. This sample size, selected using sampsi Stata command [31], is required to detect the impact of the intervention. The detailed sampling strategy and the description of the project are documented in [32]. The data were collected by trained enumerators using a structured questionnaire, which included socio-economic characteristics of the households, self-reported malaria incidence, bed net ownership and utilization, the health-seeking behaviour of the households, and costs of malaria treatment.

\section{Focus group discussions}

The objective of the focus group discussions (FGDs) was to understand residents' perceptions on malaria incidence in their locality. The district is divided in to 11 health clusters. Each health cluster has one health centre and 3 to 5 health posts. Therefore, we conducted one FGD per cluster. Thus, a total of 11 FGDs were undertaken in 11 health clusters of the district, which were purposively selected to reflect agroecological differences and information coverage across the district. The participants of the FDGs were 7-10 people per FGDs. The FDGs were undertaken by three members of the research team. The first member was responsible for leading discussion while the second researcher was tasked with taking notes. The third member recorded the discussion. All discussions and interviews were conducted based on a prepared semi-structured interview focusing on malaria knowledge, malaria control interventions and the role of indigenous knowledge in malaria control. The FGDs were held in Amharic, which is the working language of the Federal Government of Ethiopia and the mother tongue in the study area. In addition to the FGDs with the community members, local health workers were asked questions on the awareness of the communities regarding malaria illness, communities' health-seeking behaviours, common vector control interventions practiced in the area, how they performed diagnosis and treatment of patients, and challenges in malaria control and elimination in the district.

\section{Parasitological screening}

This involved a cross-sectional malaria parasitological survey to estimate Plasmodium parasite prevalence, transmission intensity, identification of specific foci of local transmission and identification of the Plasmodium species presents in the study area. This would potentially allow programme managers to prioritize severely affected villages for malaria control interventions, amid limited logistical capacity and shortage of professional experts $[33,34]$.
Information from the baseline household survey data was used to select individuals for the parasitological survey. The parasitological screening was carried out from households with at least one child aged 10 years and below. In this study, one child per household was tested. In households where more than one child under 10 was encountered, one child was randomly tested. The focus on this age cohort is because they are at higher risk of malaria than other people. This age cohort is also less mobile, which may reflect the true disease prevalence [35]. GPS coordinates of houses of each child were taken using a handheld GPS unit and study villages and households of all children were mapped.

Blood samples were collected in November and December 2019. A finger prick blood sample was collected after cleaning the finger surface using sterile cotton wool soaked in $70 \%$ ethanol by trained technicians. The thick smear was served to confirm the presence or absence of Plasmodium parasites, whereas the thin smear was fixed with methanol and stained with Giemsa (3\%, PH, 7.2, for $20 \mathrm{~min}$ ) to identify the parasite species. Microscopic examination was conducted under $100 \times$ magnifications, and 100 fields were examined before a negative result was confirmed. All blood films were initially read on-site or at local malaria control laboratories by trained laboratory technicians. Films positive for parasites and a $10 \%$ sample of films negative for parasites were subsequently checked by an independent senior laboratory technician at Finoteselam Hospital Laboratory. The parasite density (parasite $/ \mathrm{mm}^{3}$ ) was calculated by assuming an average leukocyte concentration of 8000 leukocytes $/ \mathrm{mm}^{3}$ [36]. Thus, the recorded parasite density was obtained by multiplying the observed number of parasites by 25. Prevalence of single and multiple species of parasites was assessed and classified by gender and age groups. $X^{2}$ test was used to compare the burden between gender and age group. P-value of $<0.05$ at $95 \%$ CI was used to test the statistical significance between the dependent and independent variables.

\section{Data analysis}

Demographic variables such as marital status, education, occupation, housing setting were presented using descriptive analysis. However, variables were further dichotomized between households that reported malaria and not reported malaria to determine the indicator variables. Thus, difference between households that reported malaria and not reported malaria were presented using percentile. Malaria treatment-seeking behaviour and possible sources of treatment in the area were presented using percentile. Line graphs were used to indicate trends of malaria case in study villages across villages, years, and specific months of the year. 


\section{Ethical clearance}

The stakeholders, kebele management and health sector (including zonal, district and kebele) workers in the study area were informed about the objective of the study. Consent was obtained in advance from heads of households that took part in this study. The objective of the study and participants' right to quit at any step from being part of the study was explained before the commencement of data collection. Data collectors that took part in blood sample collection were separately trained. Study subjects found positive for malaria infection during this survey were promptly treated according to the national malaria treatment guideline [37]. This study was cleared by the ethical committee of Amhara Regional State Public Health Institute, and submitted to the zonal, woreda and kebele administrations.

\section{Results}

Socio-demographic characteristics of the study subjects

The socio-demographic characteristics of the study village are presented in Table 1. Most of the households (89\%) were led by males and a similar majority (88\%) were married. More than half (55\%) of the respondents were illiterate. The overwhelming majority (98\%) of heads of the households were farmers. Each household had an average family size of 5.6. A large proportion (30\%) of the interviewed households reported having no bed nets. The number of bed nets owned by the households (1.64) was quite small relative to the average size of the households. Houses were made of wooden walls and plastered with mud. House roofs were made from corrugated iron sheet, with $57 \%$ of them without eave gaps. The eaves of the remaining $43 \%$ of houses were partially or fully open. Nearly $10 \%$ of respondents also reported that their houses were screened so that mosquitoes could not enter the house in the evening. More than half $(56 \%)$ of the community had separate cattle sheds or houses. However, $40 \%$ of the households reported that they sheltered animals within the houses.

\section{Malaria testing and treatment seeking behaviour}

Malaria treatment-seeking behaviour and economic impact due to the disease are presented in Table 2. Thus, $14 \%$ of the respondents have reported that they were ill because of malaria in 2018/19 and it took them on average 4 days before they report the case to the nearby health facility. The number of working days lost due to malaria illness in the area was reported to be on average 2.53 per person-per episode and the amount of money spent per person-episode was 18.18 USD. These costs included both direct (medical expenses) and indirect (transport, meal). A labourer in Ethiopia earns a wage of approximately 170 to $350 \mathrm{ETB}$, i.e., translated in USD as 4.5 to 8.75 . Thus, the working days lost per episode per person was estimated to be between 11.4 and 22.14 USD.

Table 1 Socio-demographic characteristics of the study subjects

\begin{tabular}{|c|c|c|c|c|c|c|c|}
\hline \multirow[t]{2}{*}{ Classification } & \multirow[t]{2}{*}{ Variable $(1=$ yes, $0=$ no) } & \multicolumn{2}{|c|}{$\begin{array}{l}\text { Households } \\
\text { reported malaria }\end{array}$} & \multicolumn{2}{|c|}{$\begin{array}{l}\text { Households } \\
\text { reported no malaria }\end{array}$} & \multirow[t]{2}{*}{ Mean difference } & \multirow[t]{2}{*}{ P-value } \\
\hline & & Mean & SD & Mean & SD & & \\
\hline Gender & Sex of the household head is male $(1 / 0)$ & 0.89 & 0.31 & 0.84 & 0.37 & 0.05 & 0.00 \\
\hline Family size & Family size & 5.3 & 1.92 & 4.75 & 1.92 & 0.55 & 0.00 \\
\hline Marital status & Married (1/0) & 0.88 & 0.33 & 0.83 & 0.38 & 0.05 & 0.00 \\
\hline \multirow[t]{3}{*}{ Education } & Illiterate (1/0) & 0.53 & 0.50 & 0.57 & 0.5 & -0.04 & 0.02 \\
\hline & Schooling $1-7$ years $(1 / 0)$ & 0.41 & 0.48 & 0.36 & 0.48 & 0.05 & 0.00 \\
\hline & Schooling above $>7$ years $(1 / 0)$ & 0.07 & 0.25 & 0.08 & 0.27 & -0.01 & 0.40 \\
\hline Occupation & Farming $(1 / 0)$ & 0.98 & 0.14 & 0.99 & 0.12 & -0.01 & 0.21 \\
\hline \multirow[t]{3}{*}{ Bed nets } & Have bed nets $(1 / 0)$ & 0.70 & 0.46 & 0.70 & 0.46 & 0.00 & 0.94 \\
\hline & Number of bed nets owned & 1.64 & 0.76 & 1.64 & 0.7586 & 0.09 & 0.86 \\
\hline & Number of rooms with bed nets & 1.83 & 1.79 & 1.63 & 1.42 & 0.20 & 0.00 \\
\hline \multirow[t]{8}{*}{ Housing characteristics } & Eave open $(1 / 0)$ & 0.18 & 0.38 & 0.16 & 0.37 & 0.01 & 0.34 \\
\hline & Eave fully closed (1/0) & 0.53 & 0.50 & 0.6 & 0.49 & -0.07 & 0.00 \\
\hline & Eave partially closed (1/0) & 0.29 & 0.45 & 0.23 & 0.42 & 0.06 & 0.00 \\
\hline & Main house screened (1/0) & 0.11 & 0.31 & 0.09 & 0.29 & 0.02 & 0.10 \\
\hline & Animals sheltered within house (1/0) & 0.42 & 0.49 & 0.4 & 0.49 & 0.02 & 0.28 \\
\hline & Animals sheltered outside house (1/0) & 0.53 & 0.49 & 0.53 & 0.5 & 0.00 & 0.89 \\
\hline & No animals (1/0) & 0.05 & 0.21 & 0.06 & 0.24 & -0.02 & 0.04 \\
\hline & Number of observations & 3010 & & & & & \\
\hline
\end{tabular}


Table 2 Reported malaria treatment-seeking behaviour and economic impact

\begin{tabular}{|c|c|c|c|c|}
\hline Variable & Mean & SD & Min. & Max. \\
\hline Members were ill because of malaria in 2018/19 (1/0) & 0.14 & 0.34 & 0 & 1 \\
\hline Number of days lost due to sickness/person & 2.53 & 5.36 & 0 & 90 \\
\hline Days before seeking treatment? & 3.96 & 7.30 & 0 & 90 \\
\hline Total out of pocket expenditure (USD) & 18.18 & 26.73 & 0 & 213.79 \\
\hline
\end{tabular}

Table 3 Reported treatment sources in the study area

\begin{tabular}{lcc}
\hline Places & Freq. & Percent \\
\hline Village clinic & 1507 & 73.01 \\
Hospital & 243 & 11.77 \\
Traditional healer & 33 & 1.6 \\
Village clinic and hospital & 92 & 4.46 \\
Village clinic and traditional healer & 16 & 0.78 \\
Hospital and traditional healer & 11 & 0.53 \\
All & 4 & 0.19 \\
Did not seek treatment & 158 & 7.66 \\
\hline
\end{tabular}

Different treatment sources used by the community members in the study area are presented in Table 3. Village clinic or health post and hospitals were reported to be the main source of treatment according to $91 \%$ of the respondents. There were a small portion of the respondents $(1.6 \%)$ who reported to use traditional healers exclusively and another small portion of respondents (7.66\%) who did not seek any treatment.

\section{Results from focus group discussion Participant's' malaria knowledge}

Under this section participants were asked to discuss and reflect the general information about the presence and absence of malaria disease in their villages, malaria disease trend in the last 5 years, the estimated number of people who became sick within their family and/or within their community, the most affected group of people, common place of work of community members in the area, time of work and malaria calendar. Accordingly, all participants of the FGD were in agreement that there were active malaria cases in their villages. However, participants underlined a significant decline in malaria cases in recent years across the villages (Table 4).

FGD participants from Fetegem, Maksegn, Kuni, Agomamit, Mankusa and Jiga estimated figures of malaria cases in their community. Accordingly, the least estimate ( 2 to 3 cases/year) was reported from Fetegem, and the highest estimate 100/year was reported from Agomamit. Despite the presence of malaria in their villages, FGD participants from Woyenema, Awunt, Yeraber and Malan indicated that they could not put forward the exact or estimated number. Malaria was transmitted through mosquito bites that occur during the night according to all participants. Malaria was reported to seasonal, occurring between April to May and Sept to November. Participants from Woyenema and Awunt however, reported that malaria occurred all year-round in their village. One respondent from Fetegem health cluster raised a very important point about how people who work in the security sector (community policing members, private security guards) were disproportionately affected by the disease. According to the respondent.

Table 4 Reported malaria disease knowledge from FGD groups, Jabi Tehnan district, NW Ethiopia

\begin{tabular}{lllll}
\hline Health cluster & Estimated malaria cases/year & Affected group & Mosquito biting time & Malaria calendar \\
\hline Fetegem & $2-3$ & Children, night guard workers, farmers & Night & April-September \\
Maksegn & $4-15$ & Children, pregnant women, farmers & Night & April-September \\
Kuni & $10-15$ & Children, pregnant women, farmers, & Night & April-September \\
Agomamit & $4-100$ & Children, pregnant women, farmers & Night & April-September \\
Mankusa & $15-50$ & Children, pregnant women, farmers & $21: 00-23: 00$ & Year round \\
Woyenema & Difficult to estimate & Children, people work in irrigated fields & $21: 00-00: 00$ & Year round \\
Awunt & Difficult to estimate & Children, people work in irrigated fields & Night & Year round \\
Jiga & 5-20 & Children, people work in irrigated fields & Night & April-September \\
Yeraber & Difficult to estimate & Children, pregnant women & Night & April-September \\
Malan & Difficult to estimate & Children, pregnant women & Night & April-September \\
\hline
\end{tabular}


"People who work in night security shifts usually get tired at some point and fall asleep in unguarded places (security huts) where they get mosquito bites and acquire the disease."

A respondent from Maksegn health cluster also added other risk factors observed in their area. These included the habit by some community members who stay outdoors until 19:00 $\mathrm{h}$, keeping livestock outside the main home and guarding them in the night which leads to infection by malaria vectors.

\section{Participant's access to and utilization of malaria control intervention}

The discussion under this heading focused on curative and preventive interventions in respective localities within the study area. The FGD participants agreed that LLINs were the only preventive intervention available in all the health clusters and IRS was available only in four villages (Fetegem, Jiga, Woyenema and Yeraber) of the district. According to the participants filling and draining of standing water was the most widely practiced supplementary intervention used to remove mosquito breeding habitats.

Despite these community and government-led efforts, there were still challenges to eliminate malaria in the study area. For instance, some community members dug water reservoirs for different purposes including preparation of mud for wall plastering and left the pits undrained. Some individuals also constructed houses for rental purposes and kept them closed for a long period of time. These uncontrolled practices of some community members often created suitable breeding and resting places for mosquitoes respectively. The other key challenge observed by FGD participants was repurposing of bed nets. Participants said that it was a common practice to see people using bed nets as bags to transport goods, repurposing them as ropes, or using the nets to cover grain stores or barley heaps (Additional file 1: Plate S1; Additional file 2: Plate S2).

Despite the overwhelming majority of FGD members noting that people can get services from health facilities which are in their own villages, on average found within a $5 \mathrm{~km}$ distance, one participant from Maksegn health cluster and another from Woyenema stated that people travelled between seven to $20 \mathrm{~km}$ to seek treatment.

\section{Participant's indigenous practices in malaria prevention and control}

Under this section, the study team probed the FGD participants on different cultural (e.g., traditional medicines) and religious practices (e.g., spiritual rituals). Participants from Fetegem health cluster stressed the predominance of modern medicine for treatment in their area but they also reported the practice of making extracts from leaf and succulent parts of Ocimun lamiifolium (local name: "damakese") in the past. Participants from Agomamit health cluster reported the practice of eating mashed garlic. In the same way participants from Maksegn health cluster revealed there was a practice of using leaf extracts from Phytolacca dodecandrian ("Indod"), Clausena anisate ("limmich"). In Awunt health cluster, FGD participants reported that they used a mix of honey, garlic, and Croton macrostachyus (local name: "Bisanna") extracts.

\section{Results of the parasitological screening}

Out of the 1256 randomly selected subjects who gave their consent for the malaria parasite test, $11(0.89 \%)$ were found to be positive (Fig. 2). Out of the 11 positive children, 6 were found in the Mankusa cluster (Goref and Abasem kebeles), 4 were found in the Woyenema cluster (Ergib Kebele), and 1 was found in Agomamit cluster (Guay kebele). Out of the 11 malaria cases identified 9 (82\%) of the samples were identified as being due to Plasmodium vivax, while the remaining 2 were Plasmodium falciparum.

According to hospital and clinic-based reports in JabiThenan district, there were a total of 3315 malaria cases documented in the months between July and December 2019. Woyenema (652 cases), Jiga (573 cases), Ergib (315) and Awunt (225 cases) were the top four malarious villages documented in the district. Plasmodium falciparum was more prevalent with a total number of 1885 (57\%) as compared to $P$. vivax which accounted for 1244 (37.5\%) (Fig. 3).

Malaria disproportionately affected the adult segment of the population as $50 \%$ of the total cases were reported from people whose age was 15 years and above. The

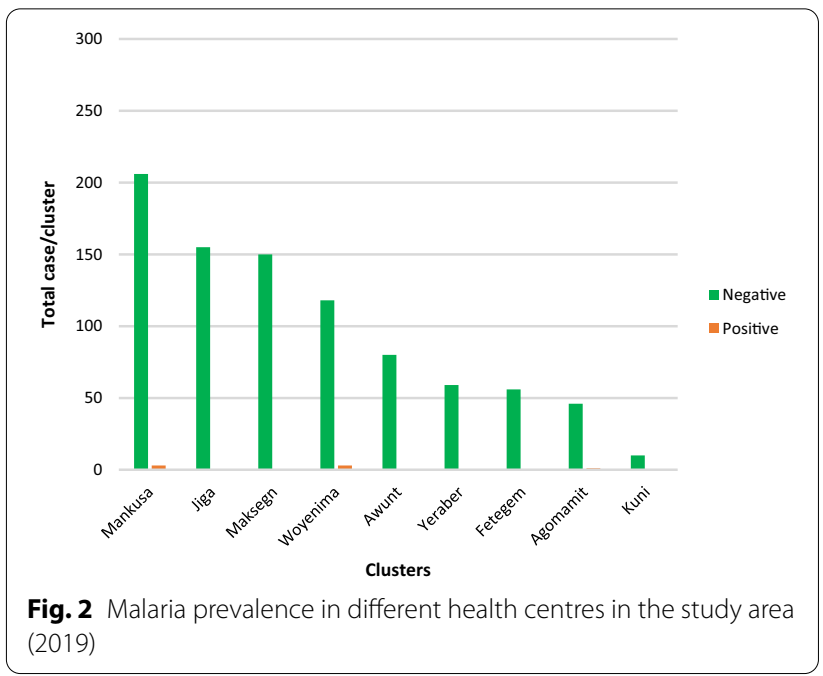




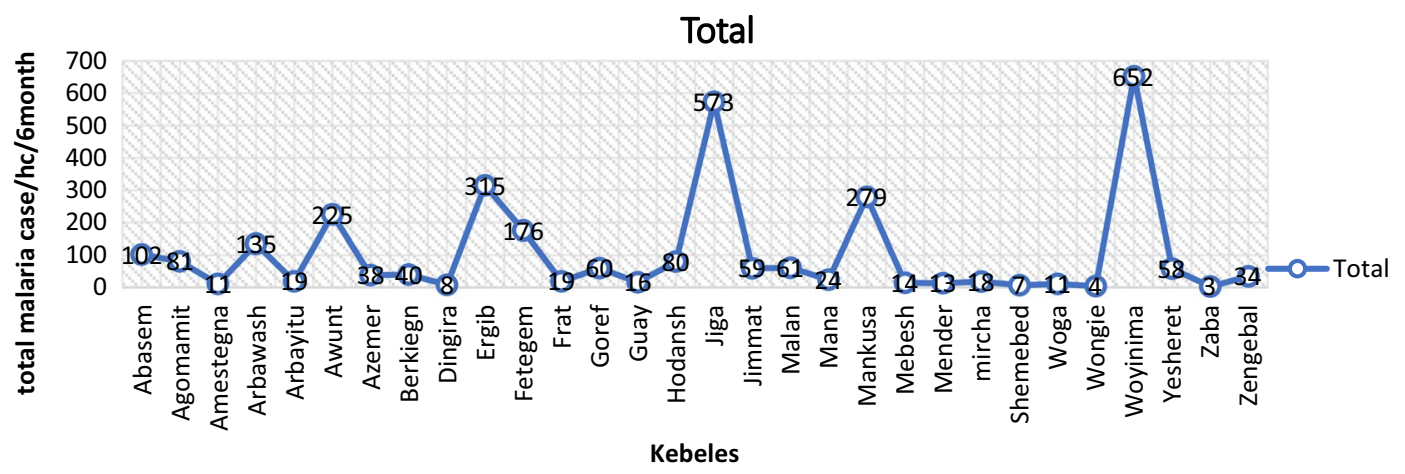

Fig. 3 Malaria case reports from health facilities by village in the study area (July-December 2019)

age group between 5 and 14 years was the second most affected group followed by children under 10 with $31 \%$ and $14 \%$ of the cases for each group, respectively (Fig. 4).

\section{Trend analysis}

Overall malaria cases in Jabi Tenan district were observed to substantially and sequentially decline during the 5 year period from 2015 to 2019. Thus, the highest number of malaria cases $(30,400)$ was documented in 2016 and the lowest number (6119) in 2019. This shows that there was $80 \%$ reduction of cases during the period. However, a comparison of the last 2 years data (2018 and 2019) showed a stagnation in case reduction (Fig. 5).

\section{Discussion}

Malaria control programme managers mainly depend on case reports from health facilities to make major intervention decisions [30]. The fact that decisions are made mainly based on case reports puts the entire programme on passive posture, i.e. if other outbreak alert and response methods such as entomological information, weather forecast, regular cross sectional malaria indicator surveys are not in place, the programme office will always left with to play catch-up to contain the disease outbreak [38]. While case reports from health facilities always remain a critical component in deriving both policy and strategic decisions, they may not sufficiently provide the necessary information regarding malaria transmission intensity, hot spots, and endemicity problem. In this study, key malaria disease control indicators were assessed in Jabi Tehnan district using household level KAP and cross-sectional malaria parasitological surveys. In addition, recent trend of malaria cases and its implication for malaria elimination was evaluated.

The socio-demographic features of community members in the study area were similar to those reported from other parts of Ethiopia including a pre-dominance of male-led households, high level of illiteracy and

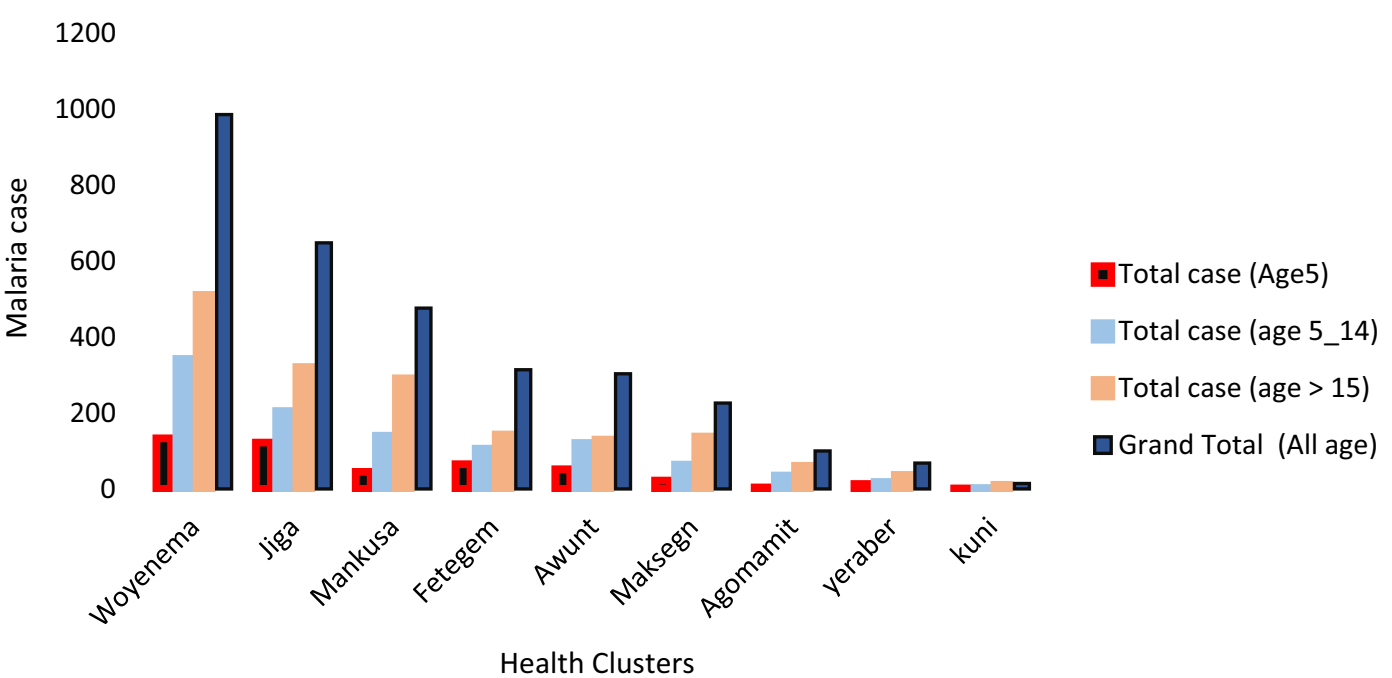

Fig. 4 Malaria burden in different age groups reported from health facilities in the study area 


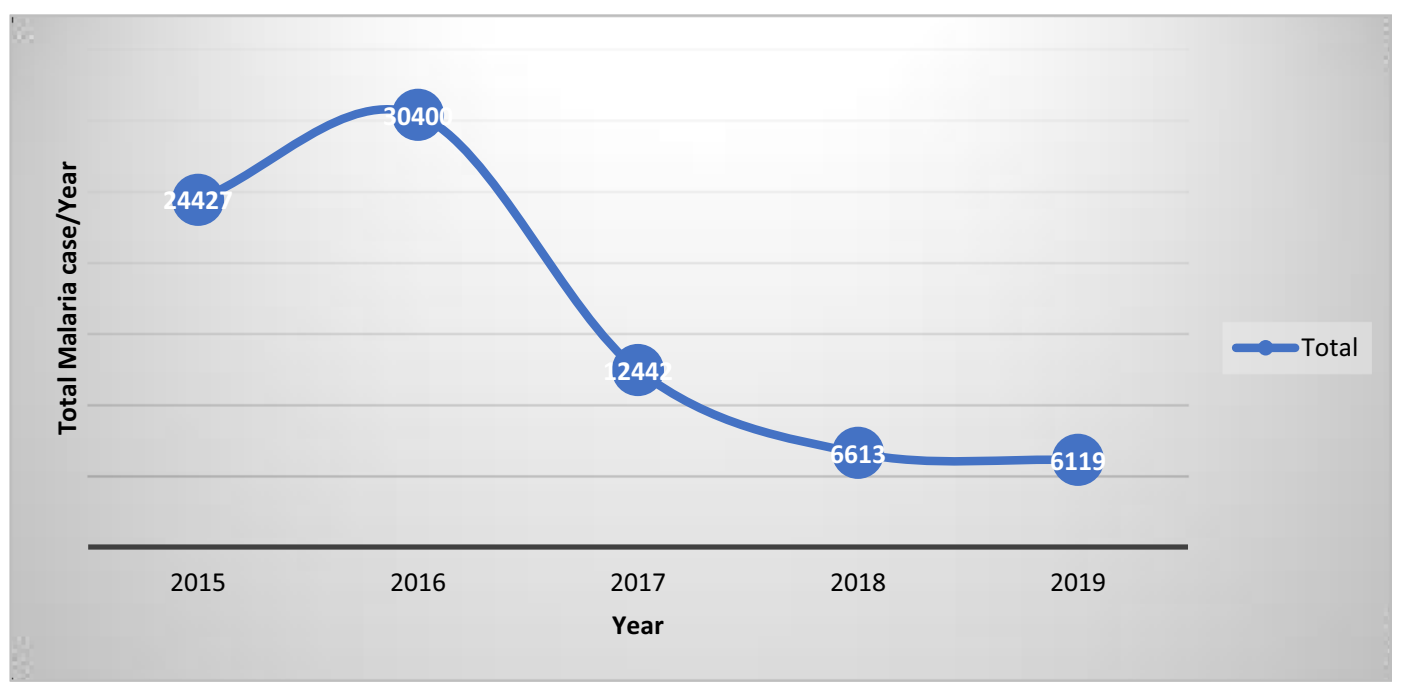

Fig. 5 Trend analysis of malaria cases reported in Jabi Tehnan district Northwestern Ethiopia (2015-2019)

engagement in agriculture as the main community occupation [39]. The average family size of 5.6 reported here is slightly higher than the country average of 4.6 [19]. It might be economically difficult for large households to buy enough insecticide-treated bed nets and this is documented in studies conducted in Gambella and Jimma, Southwestern Ethiopia [40, 41]. LLINs are freely available by the government in Ethiopia, however, a household cannot receive more than four LLINs regardless of any extended family size. This means households with extended family size are forced to buy the extra bed nets needed. Most members of the community have separate cattle sheds or houses, and this is an important behavioural difference documented compared to the reluctance of families in most parts of Ethiopia to separate cattle from human residences. Keeping livestock away from human residences is acknowledged as a practical strategy for diverting certain malaria vector species from human hosts to other vertebrate hosts, thereby, decreasing the contact between humans and infectious mosquitoes $[42,43]$. Houses in this study were made of walls with wooden frames, plastered mud walls and roofs made of corrugated iron sheets. The absence of traditional huts with grass thatched roofs could be partly explained by improved economic status of the community [44]. The coverage of households in the area with LLINs was found to be moderate, with every household having at least 0.5 LLINs and with total coverage being $70 \%$. This was below the country and regional average of $72 \%$ and $76 \%$ respectively [24].

Both long-lasting insecticidal nets (LLINs) and indoor residual spraying (Propoxur, 1-2 $\mathrm{g} \mathrm{m}^{2}$ ) were being used in the district with IRS given priority to 4 villages (Ergib,
Awunt, Hodansh and Jiga Yelimdar) which had higher ongoing transmission. LLINs was the only intervention available throughout all the health clusters of the district. Universal coverage (100\% access) was ensured in the district as confirmed through FGD, personal observation and information obtained from the district health department. Supplementary interventions such as filling and draining of standing water were reported by FGD participants even though they were not regularly implemented. Major emphasis was given to case treatment and bed net distribution from malaria control programme office of the district.

Universal coverage or access to at least one vector control intervention/per household is the direction adopted by national malaria control programme since 2006 in Ethiopia [45]. Low utilization of the already available interventions and using nets for unintended purposes however remains major challenges in the area as close to half $(50 \%)$ of the households who had access to bed nets did not use it in the previous nights in the area. Lack of persistency in using bed nets is a cross-cutting problem throughout the country as it is assessed in country wide malaria indicator surveys [24]. Continued community education and communication effort should be done in order to bring the desired behavioural changes.

As it is confirmed in this study repurposing of bed nets was reported as commonly available. Thus, there is serious gap in behavioural change to be addressed from all stakeholders involved in malaria control programmes. Studies documenting misuse of bed nets in Ethiopia are not many, but a study conducted in Adame-Tullu district of East Shewa zone, central Ethiopia showed that misuse and repurposing of bed nets for other purposes 
such as wrapping maize kernels, wrapping teff and transporting it from field to home using animal carts are the common acts of misuse [5]. The observed repurposing of LLINs can be improved through continued teaching of communities about the adverse effects of accidental contamination of cereals covered with insecticidal nets and facilitating access of target communities to cheaper and suitable materials for making ropes, transportation, or coverage of grain stores.

In this study, different traditional practices were assessed, including vector control and diseases treatment approaches used by the communities in the study area. Despite the reliance on modern medicine predominantly as the participants described, some community members believed that extracts from leaf and succulent parts of different plants such as Ocimun lamiifolium (loc. "damakese"), Phytolacca dodecandra ("Indod"), Clausena anisate ("limmich"), Croton macrostachyus ("Bisanna") and mashed garlic could be used for treating malaria. Provision of traditional medicine for malaria remedy is a longestablished trend in Ethiopia [46, 47]. While the essence of indigenous knowledge is undoubtedly important in the quest of new antibiotic options, the anti-malarial potential for the plants has not scientifically established yet.

The delayed treatment-seeking behaviour observed in this survey is also a common problem documented throughout the country with reports from Central [48], South East [49], Western [50] and Southwestern Ethiopia [51]. While the cessation of death due to malaria in Jabi Tehnan district is an achievement, the disease continues to cost considerable working days (2.53 per person-per episode) due to morbidity and money spent on treatment (18.18 USD/person/episode) and loss of income especially for people working on daily wager. The economic impact of malaria is analysed from different perspectives including the death of workers, school absenteeism, loss of family members' time due to caring, loss of savings, loss of household and farm assets [52]. The reported working days lost due to malaria is relatively low as compared to recent studies conducted on malaria economic impact in Ethiopia which estimates loss of 6.3 working days, but money spent per episode per person was relatively high as compared to the 17.8 USD expense/ episode/person [53] in Ethiopia and Kenya with loss of 5 USD [54].

Health posts and government hospitals were reported to be the main source of treatment in the area. Malaria treatment is freely accessible in Ethiopia through government health institutions (Health Posts, Health centres, and hospitals) [1]. Despite free access to malaria treatment at every village level in the district and in other parts of the country, some people either did not seek treatment at all $(7.66 \%)$ or used other unreliable treatment sources such as traditional healers (1.6\%). This showed that there are still significant gaps in the awareness level of the community in treatment-seeking behaviour. However, the fact that some community members use traditional treatment options consciously for different reasons cannot be ruled out. Avoiding travelling longer distance, seek of cheaper cost, having bad experience from medical centres in the past, influence of local traditional healers are some of the justifications reported elsewhere [55].

Malaria disease prevalence in Jabi Tehnan district was low $(0.89 \%)$. In this survey, Plasmodium vivax was the main parasite documented in the area followed by Plasmodium falciparum. Besides, all positive samples were documented in areas well below $2000 \mathrm{~m}$ above sea level, between 1300 and 18,000 m. As Jabi Tehnan is one of the 239 districts selected for all human to human malaria elimination in the country [56], the current low prevalence rate gives hope for the envisaged elimination programme. However, the recent resurgence of $P$. vivax in some of the villages (Ergib, Goref, Abasem, Jiga Yelimdar, and Guay) may jeopardize the plan.

Malaria case reports from health facilities in the area were collected concomitantly to make comparisons and cross-validations with prevalence data. Accordingly, those villages where positive cases were found in the cross-sectional survey had also the highest share of cases as reflected in clinic-based data in the district. Jiga and Awunt had reported considerably higher cases with the former being the second and the latter being fourth most affected in the district. However, no positive case was found in the cross-sectional parasite survey. Moreover, malaria disproportionately affected the adult segment of the population as $50 \%$ of the total case was reported from people whose age was 15 and above followed by the age between 5 and 14. In Ethiopia, malaria transmission is unstable and highly seasonal with few exceptions of areas bordering Sudan and South Sudan. This has resulted in low host immunity and risk of the adult population being more affected unlike the trends observed in other parts of Africa [1,57].

In this study, malaria parasite testing was done using microscopy only. This might have contributed to the observed low level of parasite prevalence. Conventional diagnostics such as microscopy and RDT have led to missing nearly half of the asymptomatic Plasmodium reservoir, which were detected by more sensitive molecular diagnostic tools such as nPCR and qPCR $[58,59]$. Thus, future parasite screening surveys should consider utilization of combination of both microscopy and molecular screening techniques.

Overall malaria cases have been substantially declined in the last 5 years in Jabi Tehnan district. Thus, the highest 
malaria case was documented in 2016 and the least case was documented in 2019 . There was $80 \%$ reduction of cases in the last 5 years, however, comparison of the last 2 years data (2018 and 2019) showed that case reduction had almost flattened. Outdoor transmission in Jabi could be driving substantial portion of transmission as the area is known for harbouring large mechanized farms, such as Bir Sheleko mechanized farm and Bir Sheleko military training campus. These sites become a point of attraction for migrant workers which mostly originate from less immune highland areas $[60,61]$. The temporary workers in these areas are usually stay in poorly constructed temporary shelters, which are called "satera", tent like structures which are made of wooden framework and partially covered with plastic cover. These structures are porous and easily allow the influx of vector mosquitoes. Moreover, the structures are constructed to accommodate multiple workers and, therefore, it is difficult to put on bed nets. This was confirmed from FGD conducted by the community members and the members agreed that temporary workers, guards, people who work until late evening are the main victims of mosquito bite. The government of Ethiopia mainly focuses on aggressive deployment of indoor based vector intervention tools (IRS and LLINs), however, the loophole created by the above conditions continued to reverse hard earned gains through indoor vector control interventions and need immediate action from policy makers. This is also a common problem across Africa as a certain portion of malaria vectors defy the existing vector control efforts [45]. It becomes clear that even with universal coverage of mainstay vector control interventions, there will be still sustained transmission due to outdoor transmission [62]. Mosquito net utilization is affected by a number of factors. These include the absence of sufficient mosquito nets, the size of the net (single, double, family) [63], education level of the user, housing setting [64], sleeping and mobility patterns of the specific community $[65,66]$. Thus, mosquito net distributions should be followed by appropriate operational researches in order to determine mosquito net utilization and the constraints against the achievement of the desired behaviour.

\section{Conclusion}

In conclusion, this study assessed the status of key malaria control interventions namely access and utilization rate of LLINs, and treatment-seeking behaviour. In both regards, there was a serious gap that must be addressed through social mobilization and education. Both cross-sectional and hospital-based positivity rate studies showed that malaria prevalence in the area was low. However, the fact that the rate of reduction did not change for the last 2 consecutive years showed that there should be a concerted effort to further drive case reports to zero. The situation, therefore, calls for the implementation of supplementary interventions such as house screening as recommended in several recent studies in both Ethiopia and other countries [67-71].

Despite the achievement of universal coverage in terms of LLINs access, utilization of vector control interventions in the area remained low. Moreover, using bed nets for unintended purposes was a major challenge. Consequently, continued community education and communication would be necessary in the study area in order to bring about the desired changes in community behaviour and practices. Community education could be more effective if delivered in more targeted approaches such as malaria education for women groups, intensified education in hotspot neighborhoods and cascading malaria education through primary schools [72, 73]. Moreover, behavioural changes may take long time (years) to achieve. Hence, positive communication approaches should be implemented to slowdown community fatigue development. These include integrating passive and active mass education [74, 75], using local approaches such as coffee ceremony [53] and artistic interventions such as songs, drams and poets [76].

In this study, it was confirmed that botanical extracts from leaf and succulent parts of different plants such as Ocimun lamiifolium (loc. "damakese"), Phytolacca dodecandra ("Indod"), Clausena anisate ("limmich"), Croton macrostachyus ("Bisanna") were being used for treatment of malaria. In addition, there were other plants being used for malaria treatment, but their names were concealed from disclosure by the healers. Therefore, the potential of these plants should be further investigated in order to identify and evaluate their active ingredients and their effectiveness for preventing or clearing malaria.

\section{Abbreviations}

LLINs: Long-lasting insecticidal nets; ITN: Insecticide treated net; IRS: Indoor residual spray; NMCP: National Malaria Control Programme; WHO: World Health Organization.

\section{Supplementary Information}

The online version contains supplementary material available at https://doi. org/10.1186/s12936-021-03996-5.

Additional file 1: Plate S1. Intact bed net is being used for unintended purpose such as transporting bag for crops from field to home (Photo courtesy: Abebe Asale).

Additional file 2: Plate S2. Intact bed net is being used for unintended purpose such as bag for animal feed or hay near home (Photo courtesy: Abebe Asale).

\section{Acknowledgements}

The authors thank the community health extension workers and Jabi Tehnan district health bureau officers for cooperating in collection of the necessary 
malaria data. We are especially grateful to West Gojjam zone health department for assisting in the selection of study villages.

\section{Authors' contributions}

AA conceived and designed the study. AA and ZA analysed the data and prepared the draft manuscript. CM and MK critically commented on the draft manuscript. All authors read and approved the final manuscript.

\section{Funding}

This study was funded by Norwegian Agency for Development Cooperation (NORAD) (Grant No. KEN-18/0005). The funding organization had no role in designing, executing and interpreting the study.

\section{Availability of data and materials}

The datasets used and/or analysed during the current study are available from the corresponding author on reasonable request. All data generated or analysed during this study are included in this article and its Additional files.

\section{Declarations}

\section{Ethics approval and consent to participate}

This study was reviewed and approved by institutional review board (IRB) of Amhara Regional Public Health Institute with ref: APHI/HRTTD/03/341/2019).

\section{Consent for publication}

Not applicable.

\section{Competing interests}

All the authors declare that they have no competing interest.

\section{Author details}

'International Center of Insect Physiology and Ecology, Addis Ababa, Ethiopia. ${ }^{2}$ International Center of Insect Physiology and Ecology, Nairobi, Kenya. ${ }^{3}$ University of Pretoria Institute for Sustainable Malaria Control, School of Health Systems and Public Health, University of Pretoria, Pretoria, South Africa.

\section{Received: 3 May 2021 Accepted: 28 November 2021}

Published online: 09 December 2021

\section{References}

1. USAID-ETHIOPIA. Ethiopia malaria operational plan FY 2019_President's Malaria Initiative. Addis Ababa: PMI-USAID; 2019.

2. Messenger LA, Shililu J, Irish SR, Anshebo GY, Tesfaye AG, Ye-Ebiyo Y, et al. Insecticide resistance in Anopheles arabiensis from Ethiopia (2012-2016): a nationwide study for insecticide resistance monitoring. Malar J. 2017; 16:469.

3. Zuber JA, Takala-harrison S. Multidrug-resistant malaria and the impact of mass drug administration. Infect Drug Resist. 2018;11:299-306.

4. Sougoufara S, Ottih EC, Tripet F. The need for new vector control approaches targeting outdoor biting anopheline malaria vector communities. Parasites Vectors. 2020;13:295.

5. Doda Z, Solomon T, Loha E, Gari T, Lindtjørn B. A qualitative study of use of long-lasting insecticidal nets (LLINs) for intended and unintended purposes in Adami Tullu, East Shewa Zone, Ethiopia. Malar J. 2018;17:69.

6. Killeen GF, Govella NJ, Mlacha YP, Chaki PP. Suppression of malaria vector densities and human infection prevalence associated with scale-up of mosquito-proofed housing in Dar es Salaam, Tanzania: re-analysis of an observational series of parasitological and entomological surveys. Lancet Planet Health. 2019;3:e132-43.

7. Pinder M, Conteh L, Jeffries D, Jones C, Knudsen J, Kandeh B, et al. The RooPfs study to assess whether improved housing provides additional protection against clinical malaria over current best practice in The Gambia: study protocol for a randomized controlled study and ancillary studies. Trials. 2016;17:275.

8. Sternberg ED, Cook J, Ahoua Alou LP, Aoura CJ, Assi SB, Doudou DT, et al. Evaluating the impact of screening plus eave tubes on malaria transmission compared to current best practice in central Côte d'Ivoire: a two armed cluster randomized controlled trial. BMC Public Health. 2018;18:894.

9. Menger DJ, Omusula P, Wouters K, Oketch C, Carreira AS, Durka M, et al. Eave screening and push-pull tactics to reduce house entry by vectors of malaria. Am J Trop Med Hyg. 2016;94:868-78.

10. Getawen SK, Ashine T, Massebo F, Woldeyes D, Lindtjørn B. Exploring the impact of house screening intervention on entomological indices and incidence of malaria in Arba Minch town, southwest Ethiopia: a randomized control trial. Acta Trop. 2018;181:84-94.

11. Mburu MM, Juurlink M, Spitzen J, Moraga P, Hiscox A, Mzilahowa T, et al. Impact of partially and fully closed eaves on house entry rates by mosquitoes. Parasites Vectors. 2018;11:383.

12. Kirby MJ, Njie M, Dilger E, Lindsay SW. Importance of eaves to house entry by anopheline, but not culicine, mosquitoes. J Med Entomol. 2009;46:505-10.

13. Gimnig JE, Slutsker L. House screening for malaria control. Lancet. 2009;374:954-5.

14. Lindsay SW, Jawara M, Paine K, Pinder M, Walraven GEL, Emerson PM. Changes in house design reduce exposure to malaria mosquitoes. Trop Med Int Health. 2003:8:512-7.

15. Animut A, Mekonnen $Y$, Shimelis D, Ephraim E. Febrile illnesses of different etiology among outpatients in four health centers in northwestern Ethiopia. Jpn J Infect Dis. 2009;62:107-10.

16. Ayalew S, Mamo H, Animut A, Erko B. Assessment of current malaria status in light of the ongoing control interventions, socio-demographic and environmental variables in Jiga area, northwest Ethiopia. PLOS ONE. 2016;11: e0146214.

17. Animut A, Balkew M, Lindtjørn B. Impact of housing condition on indoorbiting and indoor-resting Anopheles arabiensis density in a highland area, central Ethiopia. Malar J. 2013;12:393.

18. Animut A, Negash Y. Dry season occurrence of Anopheles mosquitoes and implications in Jabi Tehnan District, West Gojjam Zone, Ethiopia. Malar J. 2018;17:445.

19. Dafni A. Rituals, ceremonies and customs related to sacred trees with a special reference to the Middle East. J Ethnobiol Ethnomed. 2007:3:28.

20. Getahun M. Characterisation of agricultural soils in Cascape intervention Woredas of Amhara Region. Wageningen, NZ; 2015.

21. Tirados I, Gibson G, Young S, Torr SJ. Are herders protected by their herds? An experimental analysis of zooprophylaxis against the malaria vector Anopheles arabiensis. Malar J. 2011;10:68.

22. Deressa W, Ali A, Berhane Y. Household and socioeconomic factors associated with childhood febrile illnesses and treatment seeking behaviour in an area of epidemic malaria in rural Ethiopia. Trans R Soc Trop Med Hyg. 2007;101:939-47.

23. Misganaw A, Haregu TN, Deribe K, Tessema GA, Deribew A, Melaku YA, et al. National mortality burden due to communicable, non-communicable, and other diseases in Ethiopia, 1990-2015: findings from the global burden of disease study 2015. Popul Health Metr. 2017;15:29.

24. EPHI. Malaria indicator survey 2015. Addis Ababa: FMOH; 2016.

25. Asale A, Duchateau L, Devleesschauwer B, Huisman G, Yewhalaw D. Zooprophylaxis as a control strategy for malaria caused by the vector Anopheles arabiensis (Diptera: Culicidae): a systematic review. Infect Dis Poverty. 2017:6:160.

26. Mahande A, Mosha F, Mahande J, Kweka E. Feeding and resting behaviour of malaria vector, Anopheles arabiensis with reference to zooprophylaxis. Malar J. 2007;6:100.

27. Yohannes $\mathrm{M}$, Boelee $\mathrm{E}$. Early biting rhythm in the afro-tropical vector of malaria, Anopheles arabiensis, and challenges for its control in Ethiopia. Med Vet Entomol. 2012;26:103-5.

28. Taye B, Lelisa K, Emana D, Asale A, Yewhalaw D. Seasonal dynamics, longevity, and biting activity of anopheline mosquitoes in southwestern Ethiopia. J Insect Sci. 2016;16:6.

29. Lelisa K, Asale A, Taye B, Emana D, Yewhalaw D. Anopheline mosquitoes behaviour and entomological monitoring in Southwestern Ethiopia. J Vector Borne Dis. 2017;54:240-8.

30. PMI. U.S. President malaria intitiative. Ethiopia malaria operational plan FY 2020. Addis Ababa; 2020.

31. StataCorp. Stata statistical software: release 16. College Station: StataCorp LLC.; 2019.

32. Kassie M, Abro Z, Balew S, Bulte E, Asale A. Social networks, incentives, and diffusion of house screening and push-pull technology 
interventions in rural Ethiopia. AEA RCT Registry. 2020. https://doi.org/10. 1257/rct.5642-1.0.

33. Wongsrichanalai C, Barcus MJ, Muth S, Sutamihardja A, Wernsdorfer WH A review of malaria diagnostic tools: microscopy and rapid diagnostic test (RDT). Am J Trop Med Hyg. 2007;77:119-27.

34. Hayes RJ, Bennett S. Simple sample size calculation for cluster-randomized trials. Int J Epidemiol. 1999;28:319-26.

35. Sultana M, Sheikh N, Mahumud RA, Jahir T, Islam Z, Sarker AR. Prevalence and associated determinants of malaria parasites among Kenyan children. Trop Med Health. 2017;45:1-9.

36. Warrell DA, Gilles HM. Essential malariology. Boca Raton: CRC Press; 2002.

37. $\mathrm{FMOH}$. Diagnosis and treatment guidelines for health workers in Ethiopia. 2nd ed. Addis Ababa: Ministry of Health; 2004.

38. Maharaj R. Early warning systems for the detection of malaria outbreaks. Indian J Med Res. 2017;146:560-2.

39. Paulander J, Olsson H, Lemma H, Getachew A, San SM. Knowledge, attitudes and practice about malaria in rural Tigray, Ethiopia. Glob Health Action. 2009;2:1838.

40. Sena LD, Deressa WA, Ali AA. Predictors of long-lasting insecticidetreated bed net ownership and utilization: evidence from communitybased cross-sectional comparative study, Southwest Ethiopia. Malar J. 2013;12:406.

41. Watiro AH, Awoke W. Insecticide-treated net ownership and utilization and factors that influence their use in Itang, Gambella region, Ethiopia: cross-sectional study. Risk Manag Healthc Policy. 2016;9:101-12.

42. Franco AO, Gomes MGM, Rowland M, Coleman PG, Davies CR. Controlling malaria using livestock-based interventions: a one health approach. PLoS ONE. 2014;9: e101699.

43. Kawaguchi I, Sasaki A, Mogi M. Combining zooprophylaxis and insecticide spraying: a malaria-control strategy limiting the development of insecticide resistance in vector mosquitoes. Proc Biol Sci. 2004;271:301-9.

44. Duguma LA, Hager H. Consumption and species preference for house construction wood in central highlands of Ethiopia_implications for enhancing tree growing. J For Res. 2010;21:104-10.

45. Jima D, Getachew A, Bilak H, Steketee RW, Emerson PM, Graves PM. Malaria indicator survey 2007, Ethiopia: coverage and use of major malaria prevention and control interventions. Malar J. 2010;9:58.

46. Abera B. Medicinal plants used in traditional medicine by Oromo people, Ghimbi District, Southwest Ethiopia. J Ethnobiol Ethnomed. 2014;10:40.

47. Alebie G, Urga B, Worku A. Systematic review on traditional medicinal plants used for the treatment of malaria in Ethiopia: trends and perspectives. Malar J. 2017;16:307.

48. Deressa W, Chibsa S, Olana D. Treatment seeking of malaria patients in East Shewa Zone of Oromia, Ethiopia. Ethiop J Health Dev. 2003;17:9-15.

49. Dida N, Darega B. Treatment seeking behavior and associated factors among malaria suspected patients in Bale Zone, Southeast Ethiopia: institution-based cross-sectional study. J Fam Med. 2015;2:5.

50. Mitiku I, Assefa A. Caregivers' perception of malaria and treatment-seeking behaviour for under five children in Mandura District, West Ethiopia: a cross-sectional study. Malar J. 2017;16:144.

51. Getahun A, Deribe K, Deribew A. Determinant factors of delay in malaria treatment-seeking behaviour for under-five children in south-west Ethiopia: a case control study. Malar J. 2010;9:320.

52. Asenso-Okyere K, Asante FA, Tarekegn J, Andam KS. A review of the economic impact of malaria in agricultural development. Agric Econ. 2011;42:293-304.

53. Asale A, Kussa D, Girma M, Mbogo C, Mutero CM. Community based integrated vector management for malaria control: lessons from three years' experience (2016-2018) in Botor-Tolay district, southwestern Ethiopia. BMC Public Health. 2019;19:1318.

54. Sicuri E, Vieta A, Lindner L, Sauboin C. Economic costs of malaria in children in three sub-Saharan countries: Ghana, Tanzania and Kenya. Malar J. 2013;12:307.

55. Davy CP, Sicuri E, Ome M, Lawrence-Wood E, Siba P, Warvi G, et al. Seeking treatment for symptomatic malaria in Papua New Guinea. Malar J. 2010;9:268.

56. PMI. President's malaria initiative Ethiopia: malaria operational plan FY 2018. Addis Ababa: USAID; 2018.

57. WHO. World malaria report 2019. Geneva: World Health Organization; 2019.
58. Tadesse FG, Van Den Hoogen L, Lanke K, Schildkraut J, Tetteh K, Aseffa A, et al. The shape of the iceberg: quantification of submicroscopic Plasmodium falciparum and Plasmodium vivax parasitaemia and gametocytaemia in five low endemic settings in Ethiopia. Malar J. 2017;16:99.

59. Hailemeskel E, Tebeje SK, Behaksra SW, Shumie G, Shitaye G, Keffale M, et al. The epidemiology and detectability of asymptomatic Plasmodium vivax and Plasmodium falciparum infections in low, moderate and high transmission settings in Ethiopia. Malar J. 2021;20:59.

60. Malede A, Alemu K, Aemero M, Robele S, Kloos H. Travel to farms in the lowlands and inadequate malaria information significantly predict malaria in villages around Lake Tana, northwest Ethiopia : a matched case-control study. Malar J. 2018;17:290.

61. Schicker RS, Hiruy N, Melak B, Gelaye W. A venue-based survey of malaria, anemia and mobility patterns among migrant farm workers in Amhara Region, Ethiopia. PLoS ONE. 2015;10: e0143829.

62. WHO. Control of residual malaria parasite transmission. Geneva: World Health Organization; 2014.

63. Prakash A, Bhattacharyya DR, Mohapatra PK, Goswanti BK, Mahanta J. Community practices of using bed nets \& acceptance \& prospects of scaling up insecticide treated nets in north-east India. Indian J Med Res. 2008;128:623-9.

64. Tchinda VH, Socpa A, Keundo AA, Zeuken F, Seumen CT, Leke GF, et al. Factors associated to bed net use in CAmeroon: a retrospective study in Mfou health district in the Centre Region. Pan Afr Med J. 2012;12:112.

65. I washita H, Dida G, Futami K, Sonye G, Kaneko S, Horio M, et al. Sleeping arrangement and house structure affect bed net use in villages along Lake Victoria. Malar J. 2010;9:176.

66. Gryseels C, Grietens KP, Dierickx S, Bannister-Tyrrell M, Trienekens S, Xuan $X N$, et al. High mobility and low use of malaria preventive measures among the Jarai male youth along the Cambodia-Vietnam border. Am J Trop Med Hyg. 2015;93:810-8.

67. Massebo F, Lindtjørn B. The effect of screening doors and windows on indoor density of Anopheles arabiensis in south-west Ethiopia: a randomized trial. Malar J. 2013;12:319.

68. Ogoma SB, Lweitoijera DW, Ngonyani H, Furer B, Tanya L, Mukabana WR, et al. Screening mosquito house entry points as a potential method for integrated control of endophagic filariasis, arbovirus and malaria vectors. PLoS Negl Trop Dis. 2010;4: e773.

69. Walker N. The hygienic house: mosquito-proofing with screens. Am J Trop Med Hyg. 2010;83:963-4.

70. Jawara M, Jatta E, Bell D, Burkot TR, Bradley J, Hunt V, et al. New prototype screened doors and windows for excluding mosquitoes from houses: a pilot study in rural Gambia. Am J Trop Med Hyg. 2018;99:1475-84.

71. Killeen GF, Masalu JP, Chinula D, Fotakis EA, Kavishe DR, Malone D, et al. Control of malaria vector mosquitoes by insecticide-treated combinations of window screens and eave baffles. Emerg Infect Dis. 2017;23:782-9.

72. Ayi I, Nonaka D, Adjovu JK, Hanafusa S, Jimba M, Bosompem KM, et al. School-based participatory health education for malaria control in Ghana: engaging children as health messengers. Malar J. 2010;9:98.

73. Maccario R, Rouhani S, Drake T, Nagy A, Bamadio M, Diarra S, et al. Cost analysis of a school-based comprehensive malaria program in primary schools in Sikasso region, Mali. BMC Public Health. 2017;17:572.

74. Santos EM, McClelland DJ, Shelly CE, Hansen L, Jacobs ET, Klimentidis YC, et al. Malaria education interventions addressing bed net care and repair practices: a systematic review. Pathog Glob Health. 2020;1 14:2-15.

75. Glanz K, Bishop DB. The role of behavioral science theory in development and implementation of public health interventions. Annu Rev Public Health. 2010;31:399-418.

76. Panter-Brick C, Clarke SE, Lomas H, Pinder M, Lindsay SW. Culturally compelling strategies for behaviour change: a social ecology model and case study in malaria prevention. Soc Sci Med. 2006;62:2810-25.

\section{Publisher's Note}

Springer Nature remains neutral with regard to jurisdictional claims in published maps and institutional affiliations. 